\title{
Características agronômicas, bromatológicas e econômicas de alturas de corte para ensilagem da cultura do milho
}

\section{Agronomic, bromatologic and economical characteristics harvest heights for ensiling of corn}

\author{
Adauton Vilela de Rezende'; Diogo Junsuke Watanabe ${ }^{2}$; \\ Flávio Henrique Silveira Rabêlo ${ }^{3 *}$; Carlos Henrique Silveira Rabelo ${ }^{4}$; \\ Denismar Alves Nogueira ${ }^{5}$
}

\section{Resumo}

Objetivou-se avaliar as características agronômicas, bromatológicas e econômicas de alturas de corte para ensilagem da cultura do milho. O experimento foi conduzido em delineamento de blocos ao acaso, avaliando-se quatro alturas de colheita: 20;50;80 e $110 \mathrm{~cm}$ em relação à superfície do solo. Após 114 dias, o milho foi avaliado, constatando-se acréscimo na concentração de matéria seca (MS) do colmo, quantidade de colmo remanescente na área colhida, participação de grãos na massa ensilada e quantidade de $\mathrm{K}$ remanescente no colmo devido à elevação na altura de corte $(\mathrm{p}<0,05)$. Em resposta a esse resultado, a quantidade de massa ensilada diminuiu proporcionalmente quando o corte das plantas foi realizado em alturas mais elevadas $(\mathrm{p}<0,05)$. Na medida em que aumentou a altura de corte da planta a ser ensilada, verificou-se melhora na qualidade das silagens produzidas, com acréscimo na concentração de proteína bruta (PB) e aporte energético, ao passo que houve redução na concentração de fibra nessas silagens $(\mathrm{p}<0,05)$. Entretanto, o custo de produção das silagens aumentou sobremaneira pela utilização de alturas de corte mais elevadas, verificando um custo 4,47 vezes maior do que a ciclagem de $\mathrm{K}$ na área por meio do colmo remanescente. As características agronômicas e bromatológicas da silagem de milho melhoram com a elevação da altura de corte, mas a elevação da altura de corte inviabiliza economicamente a prática da ensilagem quando a geração de produtos finais não é computada. Desta maneira, recomenda-se que a altura de corte da planta de milho seja de no máximo $50 \mathrm{~cm}$.

Palavras-chave: Conservação de forragem, custo de produção, energia, fibra, valor nutritivo

\begin{abstract}
The aim was to evaluate agronomic, bromatologic and economical characteristics harvest heights for ensiling of corn. The trial was conducted in randomized block design and treatments corresponded to harvest heights of 20;50;80 and $110 \mathrm{~cm}$ from the soil surface. The agronomic evaluations were conducted 114 days after planting. The percentage of dry matter (DM) and productivity of stem, grain and participation of potassium remaining in the stem increased linearly with increasing cutting height
\end{abstract}

\footnotetext{
${ }^{1}$ Prof., Instituto de Ciências Agrárias, Universidade José do Rosário Vellano, UNIFENAS, Alfenas, MG. E-mail: adauton. rezende@unifenas.br

2 Discente do Curso de Mestrado em Ciência Animal, UNIFENAS, Alfenas, MG. E-mail: dwatanabe87@hotmail.com

${ }^{3}$ Discente do Curso de Doutorado em Ciências, Centro de Energia Nuclear na Agricultura, CENA/USP, Piracicaba, SP. E-mail: flaviohsr.agro@usp.br

${ }^{4}$ Discente do Curso de Doutorado em Zootecnia, Universidade Estadual Paulista "Júlio de Mesquita Filho", UNESP, Jaboticabal, SP. E-mail: carlos.zoo@hotmail.com

${ }^{5}$ Prof., Dept ${ }^{\circ}$ de Ciências Exatas, Universidade Federal de Alfenas, UNIFAL, Alfenas, MG. E-mail: denismar@unifal-mg.edu.br

* Autor para correspondência
} 
$(p<0.05)$. Therefore, the mass used at ensiling decreased proportionally with increasing cutting height $(p<0.05)$. The silage quality was improved because of the increase in the cutting height. We observed higher crude protein (CP) content and energetic value in the silage harvested at $110 \mathrm{~cm}$ from the soil surface, while there was lower fiber content. However, silages produced with plants harvested at 110 $\mathrm{cm}$ from the soil surface showed the highest production cost (4.47 times greater than cycling through $\mathrm{K}$ in the remainder of the stem). The agronomic and bromatologic characteristics of corn silage improves with increasing cutting height, but the increase cutting height unfeasible economically the practice silage when the generation of final products is not computed. Thus, it is recommended that the cutting height of the corn plant is at most $50 \mathrm{~cm}$.

Key words: Energy, fiber, forage conservation, production cost, nutritive value

\section{Introdução}

A busca por alimentos de adequado valor nutritivo em sistemas de produção que utilizam animais com alto potencial produtivo sempre é um desafio aos produtores (RABÊLO et al., 2013a). Nesse sentido, a silagem de milho tem sido um dos principais volumosos utilizados em sistemas leiteiros e na produção de gado de corte (DEMINICIS et al., 2009; MILLEN et al., 2009; VAZ et al., 2010) por apresentar qualidade nutricional superior às demais culturas destinadas ao processo de ensilagem no Brasil.

Entretanto, a qualidade da silagem pode ser ainda mais explorada, elevando-se a altura de corte das plantas no momento da colheita (VASCONCELOS et al., 2005). Essa estratégia reduz a concentração de fibra e aumenta a participação de grãos na massa ensilada (CAETANO et al., 2011), permitindo aumentar a produção de leite (LAUER, 1998; NEYLON; KUNG JUNIOR, 2003) em decorrência do maior aporte energético nessas silagens (RESTLE et al., 2002).

Por outro lado, a elevação da altura de corte diminui o volume de massa ensilada (LAUER, 1998), o que pode se tornar fator decisivo na receita líquida da propriedade (WU; ROTH, 2005), inviabilizando essa prática. Conforme relatado por Nussio, Campos e Dias (2001), o corte mais elevado das plantas de milho (abaixo da espiga) em comparação àqueles rentes ao solo, diminui o retorno econômico por tonelada de massa seca por hectare, o que gera dúvidas sobre essa prática quanto à produção de silagem. Ainda de acordo com os mesmos autores, a elevação da altura de corte deve contribuir para aumentar a ciclagem de matéria orgânica no solo, melhorando os atributos físicos do mesmo, além de possibilitar o retorno de grandes quantidades de potássio que se encontram nos internódios inferiores da planta.

Portanto, objetivou-se avaliar as características agronômicas, bromatológicas e econômicas de alturas de corte para ensilagem da cultura do milho.

\section{Material e Métodos}

O estudo foi conduzido na Universidade José do Rosário Vellano, campus de Alfenas - MG, localizado a $880 \mathrm{~m}$ de altitude. O experimento foi implantado em solo classificado como Latossolo Amarelo (Tabela 1). Após interpretação da análise química realizada na área, efetuou-se a correção do solo 45 dias antes do plantio visando elevar a saturação por bases a 70\%. Posteriormente, o solo da área experimental foi preparado por meio de uma aração e duas gradagens. Para o plantio do milho foram abertos sulcos a $10 \mathrm{~cm}$ de profundidade, espaçados a $80 \mathrm{~cm}$ entre linhas.

O plantio do milho (híbrido BM3061) foi realizado em novembro de 2010 (Figura 1) utilizando-se 10 sementes por metro linear. Quando as plantas apresentaram $20 \mathrm{~cm}$ de altura foi realizado o desbaste, mantendo-se cinco plantas por metro linear. A adubação de plantio foi calculada com base na análise química do solo, aplicando- 
se $350 \mathrm{~kg} \mathrm{ha}^{-1}$ da fórmula 08-28-16 ( $\mathrm{N}_{-} \mathrm{P}_{2} \mathrm{O}_{5}-\mathrm{K}_{2} \mathrm{O}$ ). ha ha $^{-1}$ de $\mathrm{N}$ (uréia) e $70 \mathrm{~kg} \mathrm{ha}^{-1}$ de $\mathrm{K}_{2} \mathrm{O}$ (cloreto de A adubação em cobertura foi realizada quando potássio). O controle das plantas invasoras foi as plantas apresentaram quatro pares de folhas realizado por meio da aplicação do pré-emergente totalmente expandidas, com a aplicação de $70 \mathrm{~kg}$ Primestra Gold $^{\circledR}$, na dosagem de $5 \mathrm{~L} \mathrm{ha}^{-1}$.

Tabela 1. Características químicas do solo utilizado na implantação do experimento nas profundidades de 0-20 cm e $20-40 \mathrm{~cm}$.

\begin{tabular}{|c|c|c|c|c|c|c|c|}
\hline Camada & $\mathrm{pH}$ & P - Mehlich & $\mathrm{K}^{+}$ & $\mathrm{Ca}^{2+}$ & $\mathrm{Mg}^{2+}$ & $\mathrm{Al}^{3+}$ & $\mathrm{H}+\mathrm{Al}$ \\
\hline$(\mathrm{cm})$ & $\left(\mathrm{H}_{2} \mathrm{O}\right)$ & \multicolumn{2}{|c|}{------mg dm-3------ } & \multicolumn{4}{|c|}{-------------------cmol $\mathrm{dm}_{\mathrm{c}}{ }^{-3}$---------------- } \\
\hline $0-20$ & 5,4 & 3,0 & 44 & 1,7 & 0,8 & 0,4 & 4,5 \\
\hline $20-40$ & 5,4 & 2,0 & 32 & 1,5 & 0,6 & 0,4 & 4,5 \\
\hline Camada & SB & $\mathrm{T}$ & $\mathrm{T}$ & $\mathrm{V}$ & $\mathrm{m}$ & M.O. & P-rem \\
\hline$(\mathrm{cm})$ & \multicolumn{3}{|c|}{-----------cmol $\mathrm{dm}^{-3}$---------- } & \multicolumn{2}{|c|}{------------0\%------------ } & $\mathrm{g} \mathrm{kg}^{-1}$ & $\mathrm{mg} \mathrm{L}^{-1}$ \\
\hline $0-20$ & 2,6 & 3,0 & 7,1 & 37 & 13 & 31 & 14 \\
\hline $20-40$ & 2,2 & 2,6 & 6,7 & 33 & 15 & 28 & 14 \\
\hline
\end{tabular}

$(\mathrm{H}+\mathrm{Al})=$ acidez potencial; $\mathrm{SB}=$ soma de bases; $\mathrm{t}=\mathrm{CTC}$ efetiva; $\mathrm{T}=\mathrm{CTC}$ potencial; $\mathrm{V}=$ saturação por bases; $\mathrm{m}$ = saturação por alumínio; M.O. = matéria orgânica; P-rem = fósforo remanescente.

Fonte: Elaboração dos autores.

Figura 1. Temperaturas mínima, máxima e precipitação pluviométrica durante o período experimental.

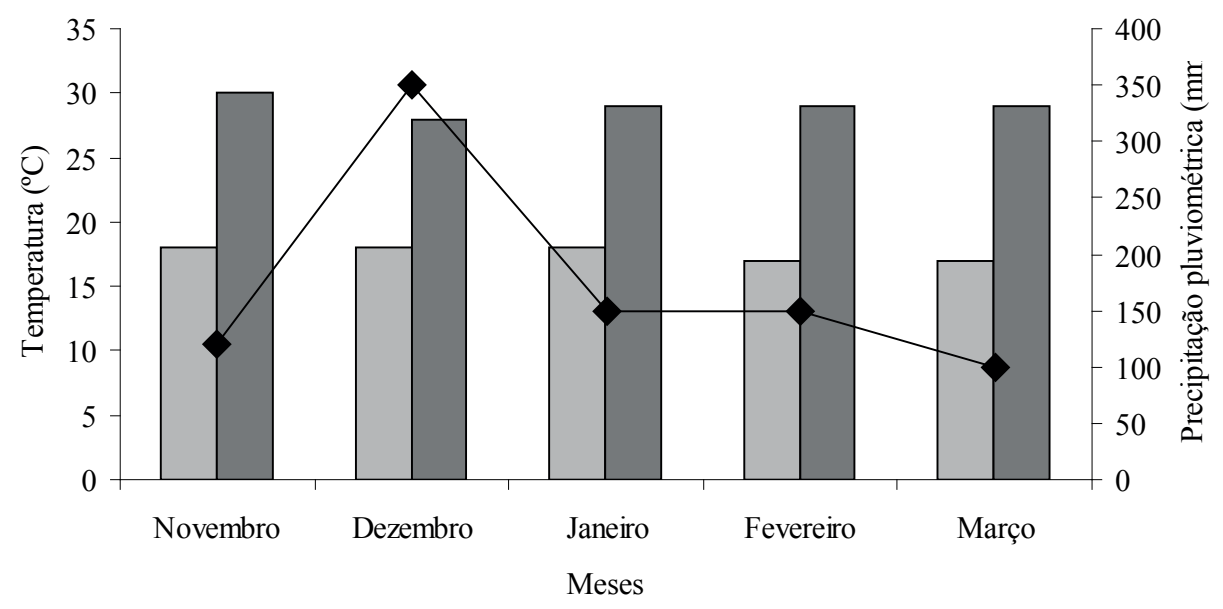

\footnotetext{
$\square$ Temperatura mínima $\left({ }^{\circ} \mathrm{C}\right) \square$ Temperatura máxima $\left({ }^{\circ} \mathrm{C}\right) \multimap$ Precipitação pluviométrica $(\mathrm{mm})$
} Fonte: Elaboração dos autores.

Os tratamentos avaliados foram alturas de corte das plantas de milho: 20; 50; 80 e 110 cm em relação à superfície do solo. Utilizou-se o delineamento em blocos ao acaso, com quatro repetições por tratamento. A parcela experimental foi constituída por quatro linhas de $4 \mathrm{~m}$ de comprimento com espaçamento de $80 \mathrm{~cm}$ entre linhas e bordadura de 1 $\mathrm{m}$ entre parcelas. Entretanto, foi considerado como área útil da parcela somente as duas linhas centrais.

A colheita do milho foi realizada 114 dias após o plantio, quando a planta apresentou estádio fenológico de $2 / 3$ da linha de leite. No dia da colheita do milho, mediu-se a altura das plantas tomando-se 
uma amostra de 10 plantas da parcela útil. A medida foi realizada em relação ao nível do solo até o ponto de inserção da folha bandeira. Do mesmo modo, a altura de inserção da primeira espiga foi realizada considerando-se o nível do solo até o ponto de inserção da primeira espiga.

Após a colheita foram avaliados a produtividade de massa seca (MS) dos colmos, parte aérea e grãos. Determinou-se o teor de MS após pré-secagem por 72 horas em estufa com ventilação forçada de ar a $55^{\circ} \mathrm{C}$. A concentração de potássio no colmo foi determinada após digestão nítrico-perclórica, com leitura em fotômetro de chama. A quantidade de $\mathrm{K}$ remanescente no colmo foi calculada multiplicandose a concentração de K pela produção de MS do colmo.

$\mathrm{Na}$ análise econômica, a concentração de $\mathrm{K}$ foi transformada em $\mathrm{K}_{2} \mathrm{O}$. Para finalidade de cálculo, considerou-se o valor médio de $\mathrm{R} \$ 1,40$ o quilograma de $\mathrm{KCl}$ com $60 \%$ de $\mathrm{K}_{2} \mathrm{O}$ (cotação realizada em novembro de 2011), o que resultou no valor de $\mathrm{R} \$ 2,33$ o quilograma de $\mathrm{K}_{2} \mathrm{O}$. Adotou-se o custo médio de $\mathrm{R} \$ 100,00$ a tonelada de silagem com 38,8\% de MS, resultando na produção de 388 $\mathrm{kg} \mathrm{ha}^{-1}$ de MS por tonelada de silagem produzida (massa verde), com valor de $\mathrm{R} \$ 257,86$ (tonelada de MS).

$\mathrm{Na}$ confecção das silagens, as plantas de cada parcela foram colhidas manualmente e picadas em partículas com tamanho médio de 1 a $2 \mathrm{~cm}$, visando obter adequada compactação da massa ensilada (massa específica entre 550 e $600 \mathrm{~kg} \mathrm{~m}^{-3}$ ). Utilizaram-se como silos experimentais, tubos de PVC (10 cm de diâmetro, $50 \mathrm{~cm}$ de altura e volume $0,0039 \mathrm{~m}^{3}$ ). Colocou-se $0,5 \mathrm{~kg}$ de areia em cada silo separando-a da silagem por duas telas de sombreamento artificial (50\%) no intuito de captar os efluentes produzidos. Após o enchimento, os silos foram fechados com tampas dotadas de válvula tipo Bünsen e lacrados com fita adesiva.

Decorridos 30 dias da ensilagem, os silos foram abertos e o conteúdo superior $(10 \mathrm{~cm})$ de cada silo foi descartado (material deteriorado). O material central do silo foi homogeneizado e amostrado para determinação da MS da silagem. Após pré-secagem, as amostras foram picadas em moinho do tipo Willey com peneira contendo crivos de $1 \mathrm{~mm}$, sendo submetidas à análise laboratorial. As concentrações de MS, cinzas, extrato etéreo (EE) e nitrogênio total (NT) foram determinadas utilizando os métodos descritos pela AOAC (1996). A concentração de proteína bruta $(\mathrm{PB})$ foi obtida pelo produto da multiplicação do teor de NT e o fator de conversão 6,25. Determinaram-se as concentrações de fibra em detergente neutro (FDN) e fibra em detergente ácido (FDA) de acordo com Van Soest, Robertson e Lewis (1991). A lignina foi determinada após solubilização em ácido sulfúrico 72\% (VAN SOEST; ROBERTSON, 1985). Os valores de $\mathrm{pH}$ foram determinados em solução aquosa (SILVA; QUEIROZ, 2002).

O teor de nutrientes digestíveis totais (NDT) foi obtido por meio da equação 1 descrita por Cappelle et al. (2001). Os valores de energia digestível (ED) e energia metabolizável (EM) foram obtidos utilizando-se as equações 2 e 3, respectivamente, descritas por Rodrigues (2009).

$$
\begin{aligned}
& \% \mathrm{NDT}=91,6086-(0,669233 \times \% \mathrm{FDN})+ \\
& (0,437932 \times \% \mathrm{~PB}) 87,84-(0,7 \times \% \text { FDA }) \\
& \mathrm{ED}(\text { Mcal kg-1 de MS })=\% \text { NDT x } 0,04409 \\
& \mathrm{EM}\left(\text { Mcal kg }{ }^{-1} \text { de MS }\right)=\text { ED x } 0,82
\end{aligned}
$$

Os dados foram submetidos à análise de variância utilizando-se o programa estatístico SISVAR $^{\circledR}$ (FERREIRA, 2011), realizando-se estudo de regressão para as alturas de corte na cultura do milho para ensilagem a um nível de significância de $5 \%$.

\section{Resultados e Discussão}

A altura da planta (média de 2,86 m) e altura de inserção da primeira espiga (média de 1,69 m) foram tomadas antes do corte para ensilagem 
no intuito de caracterizar as plantas e o híbrido utilizado no experimento, pois essas variáveis alteram sobremaneira a produtividade da cultura.

A concentração de MS do colmo aumentou linearmente $(p<0,05)$ com a elevação da altura de corte, notando-se acréscimo de 0,08 unidades percentuais para cada centímetro elevado, o que é decorrente da maior concentração de fibra e folhas senescentes nessa fração. Do mesmo modo, a quantidade de colmo remanescente na área destinada à colheita aumentou $(\mathrm{p}<0,05) 45 \mathrm{~kg}$ para cada centímetro elevado na altura de corte (Tabela 2).

Tabela 2. Características agronômicas da planta de milho colhida em diferentes alturas de corte e ciclagem de K.

\begin{tabular}{|c|c|c|c|c|c|c|}
\hline \multirow{2}{*}{ Item $^{1}$} & \multicolumn{4}{|c|}{ Altura de corte $(\mathrm{cm})$} & \multirow{2}{*}{ Equação } & \multirow{2}{*}{$\mathrm{r}^{2}$} \\
\hline & 20 & 50 & 80 & 110 & & \\
\hline \multicolumn{7}{|l|}{ Colmo } \\
\hline MS (\%) & 15,75 & 18,15 & 20,55 & 22,95 & $Y=14,159+0,08 x$ & 0,97 \\
\hline Produtividade $\left(\mathrm{t} \mathrm{ha}^{-1}\right)$ & 1,00 & 2,37 & 3,74 & 5,11 & $Y=87,198+45,676 x$ & 0,99 \\
\hline $\mathrm{K}(\%)$ & 2,05 & 2,19 & 1,94 & 2,07 & $\mathrm{Y}=2,06$ & - \\
\hline $\mathrm{K}$ remanescente $\left(\mathrm{kg} \mathrm{ha}^{-1}\right)$ & 17,53 & 45,07 & 72,61 & 100,15 & $Y=-0,823+0,918 x$ & 0,99 \\
\hline $\operatorname{PMSPA}^{2}\left(\mathrm{t} \mathrm{ha}^{-1}\right)$ & 17,87 & 16,81 & 15,75 & 14,69 & $Y=18,579-0,0353 x$ & 0,97 \\
\hline \multicolumn{7}{|l|}{ Grãos } \\
\hline Produtividade $\left(\mathrm{t} \mathrm{ha}^{-1}\right)$ & 9,04 & 9,33 & 9,10 & 9,14 & $\mathrm{Y}=9,14$ & - \\
\hline$\%$ na massa ensilada & 51,10 & 54,67 & 58,24 & 61,81 & $Y=48,726+0,119 x$ & 0,94 \\
\hline
\end{tabular}

${ }^{1}$ Equações de regressão e coeficientes de determinação $\left(\mathrm{r}^{2}\right)$ das variáveis avaliadas nas plantas de milho. ${ }^{2} \mathrm{PMSPA}=$ produção de massa seca da parte aérea.

Fonte: Elaboração dos autores.

Embora a concentração de $\mathrm{K}$ no colmo não tenha sido alterada ( $\mathrm{p}>0,05)$, a quantidade de $\mathrm{K}$ remanescente aumentou linearmente $(p<0,05)$, com acréscimos de $918 \mathrm{~g} \mathrm{ha}^{-1}$ para cada centímetro elevado na altura de corte (Tabela 2). De acordo com Nussio, Campos e Dias (2001), as plantas colhidas em altura mais elevada contribuem para aumentar a ciclagem de matéria orgânica no solo e retornam grandes quantidades de $\mathrm{K}$, que se concentra nos internódios inferiores da planta, melhorando os atributos de fertilidade do solo.

Houve redução na produtividade de $\mathrm{MS}$ da parte aérea da cultura do milho de $35 \mathrm{~kg} \mathrm{ha}^{-1}$ para cada centímetro elevado na altura de corte $(p<0,05$; Tabela 2). Embora esse seja um resultado esperado pelo uso da estratégia de melhorar a qualidade da silagem por meio da elevação da altura de corte, o conhecimento da variação na produção de MS é um fator que interfere sobremaneira na escolha em adotar ou não esse procedimento. Os resultados encontrados estão de acordo com Restle et al. (2002), os quais relataram menor rendimento na produção de MS quando as plantas de milho foram colhidas em altura mais elevada (42 vs. $20 \mathrm{~cm})$.

Não houve efeito $(p>0,05)$ da altura de corte na produtividade de grãos, visto que essa mensuração independe da altura de colheita, pois o corte mais elevado $(110 \mathrm{~cm})$ foi realizado abaixo das espigas. No entanto, a porcentagem de grãos na massa ensilada aumentou 0,11 pontos percentuais para cada centímetro elevado na altura de corte $(\mathrm{p}<0,05$; Tabela 2$)$, pois a produtividade de grãos é mantida enquanto a produção de MS declina concomitantemente. Salienta-se que a proporção de grãos na massa ensilada afeta sensivelmente a qualidade nutritiva da silagem produzida devido 
à redução na concentração de fibra e aumento da digestibilidade da matéria orgânica e do valor energético, já que dois terços do NDT no milho provém das espigas (NUSSIO, 1993).

Tomando-se por base as características das plantas de milho apresentadas nesse estudo, realizou-se uma simulação de custo da silagem e da ciclagem de $\mathrm{K}$ na área (Tabela 3 ). Com a elevação da altura de corte constatou-se que há aumento na ciclagem de $\mathrm{K}$, o que diminui os custos necessários com adubação na área (RABÊLO et al., 2013b). Todavia, o custo da silagem ( $\mathrm{R} \$ /$ ha) produzida aumentou sobremaneira, demonstrando que a elevação da altura de corte pode ser inviável em um primeiro momento, por não computar a geração de produtos finais, como carne e leite, que podem ser maximizados com a melhoria na qualidade da silagem. Embora alguns trabalhos relatem aumento na produção de leite devido à melhoria na qualidade das silagens produzidas a partir de plantas colhidas em maiores alturas (NEYLON; KUNG JUNIOR, 2003; OLIVEIRA et al., 2011), a lucratividade do sistema irá depender do potencial genético dos animais e da manutenção na concentração de gordura no leite (WU; ROTH, 2005), visto que o produtor é remunerado também pela concentração de sólidos totais no leite.

Tabela 3. Simulação de custo em função da altura de corte, massa não ensilada e ciclagem de $\mathrm{K}_{2} \mathrm{O}$ pelo colmo.

\begin{tabular}{lcccc}
\hline Altura de corte & $\begin{array}{c}\text { Massa não ensilada } \\
\left(\mathrm{t} \mathrm{ha}^{-1} \mathrm{de} \mathrm{MS}\right)\end{array}$ & $\begin{array}{c}\text { Ciclagem de } \mathrm{K}_{2} \mathrm{O} \\
\left(\mathrm{kg} \mathrm{ha}^{-1}\right) \text { pelo colmo }\end{array}$ & $\begin{array}{c}\text { Custo da silagem } \\
(\mathrm{R} \$ / \mathrm{ha})\end{array}$ & $\begin{array}{c}\text { Custo da ciclagem } \\
(\mathrm{R} \$ / \mathrm{ha})\end{array}$ \\
\hline $20 \mathrm{~cm}$ a $50 \mathrm{~cm}$ & 1,22 & 30,09 & 313,88 & 70,11 \\
$20 \mathrm{~cm}$ a $80 \mathrm{~cm}$ & 2,88 & 71,11 & 741,82 & 165,70 \\
$20 \mathrm{~cm}$ a $110 \mathrm{~cm}$ & 4,01 & 99,24 & 1035,18 & 231,23 \\
\hline
\end{tabular}

Fonte: Elaboração dos autores.

Neumann et al. (2007) verificaram que o custo total com implantação, manejo, colheita e ensilagem do milho diminuem com a elevação da altura de corte. Contudo, o custo estimado para a produção de silagem não é alterado por essa estratégia.

Nesse estudo, constatou-se que pela quantidade de massa não ensilada devido à elevação da altura de corte, o custo da silagem se torna 4,47 vezes mais oneroso em relação ao benefício da ciclagem de $\mathrm{K}_{2} \mathrm{O}$ pelo colmo na área colhida. Wu e Roth (2005) simularam a análise econômica de um sistema de produção leiteira tomando por base dois trabalhos conduzidos nos Estados Unidos da América que avaliaram alturas de corte das plantas de milho e a qualidade das silagens produzidas. Os autores observaram que no panorama avaliado, o sistema causa ligeiro prejuízo ao produtor (US\$22,24 por hectare), devido à redução na produção de leite por hectare (LEWIS; COX; CHERNEY, 2004).

Com relação aos padrões de qualidade da silagem, não foi verificado efeito das alturas de corte nos valores de $\mathrm{pH}$, contudo, esses permaneceram dentro da faixa adequada para permitir boa fermentação em silagem de milho, entre 3,8 e 4,2 (ÍTAVO et al., 2006). Constatou-se aumento de 0,08 pontos percentuais na concentração de MS para cada centímetro elevado na altura do corte $(p<0,05$; Tabela 4), o que se deve à maior participação de espigas na massa ensilada, que normalmente é mais seca que folhas e colmo (KUNG JUNIOR et al., 2008; NEYLON; KUNG JUNIOR, 2003). Esses resultados estão de acordo com Pedó et al. (2009), cujos autores observaram acréscimo na concentração de MS de silagens de milho colhidas em diferentes alturas. 
Tabela 4. Composição bromatológica (\% na MS) e valor energético de silagens de milho produzidas a partir de plantas colhidas em diferentes alturas.

\begin{tabular}{|c|c|c|c|c|c|c|}
\hline \multirow{2}{*}{ Item $^{1}$} & \multicolumn{4}{|c|}{ Altura de corte $(\mathrm{cm})$} & \multirow{2}{*}{ Equação } & \multirow{2}{*}{$\mathrm{r}^{2}$} \\
\hline & 20 & 50 & 80 & 110 & & \\
\hline $\mathrm{pH}$ & 3,95 & 3,98 & 3,87 & 3,90 & $\mathrm{Y}=3,93$ & - \\
\hline MS & 34,51 & 36,97 & 39,43 & 41,89 & $\mathrm{Y}=32,87+0,082 \mathrm{x}$ & 0,97 \\
\hline Cinzas & 3,68 & 3,44 & 3,20 & 2,96 & $\mathrm{Y}=3,837-0,008 \mathrm{x}$ & 0,95 \\
\hline PB & 8,30 & 13,40 & 18,50 & 23,60 & $\mathrm{Y}=4,899+0,017 \mathrm{x}$ & 0,99 \\
\hline EE & 3,97 & 4,16 & 4,23 & 4,32 & $\mathrm{Y}=4,17$ & - \\
\hline FDN & 56,37 & 53,73 & 51,09 & 48,45 & $Y=58,134-0,088 x$ & 0,98 \\
\hline FDA & 39,69 & 36,96 & 34,23 & 31,50 & $\mathrm{Y}=41,512-0,091 \mathrm{x}$ & 0,99 \\
\hline Celulose & 30,81 & 29,70 & 28,59 & 27,48 & $Y=31,551-0,037 x$ & 0,92 \\
\hline Lignina & 3,96 & 3,70 & 3,42 & 3,15 & $Y=4,151-0,0091 x$ & 0,99 \\
\hline \multicolumn{7}{|l|}{ NDT } \\
\hline$\%$ & 60,06 & 61,98 & 63,90 & 65,82 & $Y=58,781+0,064 x$ & 0,99 \\
\hline Produtividade $\left(\mathrm{t} \mathrm{ha}^{-1}\right)$ & 10,75 & 10,40 & 10,05 & 9,71 & $Y=10,985-0,0116 x$ & 0,94 \\
\hline ED (Mcal kg-1 MS) & 2,63 & 2,69 & 2,75 & 2,81 & $Y=2,594+0,002 x$ & 0,99 \\
\hline EM (Mcal kg-1 MS $)$ & 2,17 & 2,23 & 2,29 & 2,35 & $\mathrm{Y}=2,127+0,002 \mathrm{x}$ & 0,99 \\
\hline
\end{tabular}

$\mathrm{MS}=$ matéria seca; $\mathrm{PB}=$ proteína bruta; $\mathrm{EE}=$ extrato etéreo; $\mathrm{FDN}=$ fibra em detergente neutro; FDA = fibra em detergente ácido; NDT = nutrientes digestíveis totais; ED = energia digestível; EM = energia metabolizável.

Fonte: Elaboração dos autores.

A concentração de cinzas reduziu linearmente com a elevação da altura de corte, apresentando teores abaixo de 4\% $(p<0,05)$. A concentração de PB aumentou em 0,017 pontos percentuais por centímetro elevado na altura de corte $(p<0,05$; Tabela 4) devido ao grão de milho apresentar maior concentração desse nutriente em relação ao colmo. Esse resultado é corroborado por Lewis, Cox e Cherney (2004), os quais observaram acréscimo na concentração de PB em plantas de milho colhidas em alturas de corte mais elevadas.

Embora as maiores alturas de corte tenham proporcionado maior participação de grãos na massa ensilada, isto não influenciou o teor de EE, que se manteve igual em todos os tratamentos (Tabela 4). Sabe-se que os grãos de milho apresentam maior concentração de EE em relação à planta inteira, no entanto, normalmente o teor de EE em silagens de milho não é responsivo aos tratamentos, ou seja, independente do tratamento que está sendo avaliado. Usualmente este parâmetro não é alterado, ou quando há alteração, normalmente as causas são atribuídas a outros fatores, como efeito de diluição ou concentração sobre as demais frações do alimento.

As concentrações de FDN, FDA, celulose e lignina diminuíram linearmente com a elevação da altura de corte $(p<0,05$; Tabela 4$)$, o que se deve à maior proporção de grãos na massa ensilada nas alturas de corte mais elevadas. A redução na concentração de fibra, especialmente em relação à lignina é um fator positivo, pois, essa fração é um dos principais fatores limitantes a degrabilidade da parede celular (VAN SOEST, 1994), o que repercute em maior tempo para esvaziamento do rúmen e menor consumo pelos animais (FREITAS et al., 2006). Vasconcelos et al. (2005) reportaram redução na concentração de FDN e FDA em silagem de milho produzida com plantas colhidas a $80 \mathrm{~cm}$ do solo, comparativamente àquelas colhidas a $10 \mathrm{~cm}$.

Os valores de NDT aumentaram de forma linear $(0,064$ pontos percentuais por centímetro) com a elevação da altura de corte da planta de milho 
$(\mathrm{p}<0,05$; Tabela 4). Esse resultado se deve à maior participação de grãos na massa ensilada, resultando em maior concentração de $\mathrm{PB}$ e redução da fração fibrosa. Conforme descrito por Van Soest (1994), a parede celular é a fração da planta mais resistente à ação dos microrganismos presentes no rúmen e, normalmente, alimentos que contêm menor conteúdo de parede celular apresentam maior conteúdo de nutrientes digestíveis. Do mesmo modo, os valores de ED e EM aumentaram linearmente com a elevação da altura de corte, enquanto a quantidade de NDT disponível por hectare reduziu $(p<0,05$; Tabela $4)$, em função da menor quantidade de material ensilado. A concentração de NDT encontrada nesse trabalho é similar aos dados reportados por Oliveira et al. (2011), os quais relataram acréscimo nessa variável com a elevação da altura de corte do milho de 15 para $55 \mathrm{~cm}$.

O maior aporte energético em silagens produzidas a partir de plantas colhidas em maior altura é um fator positivo que deve ser levado em consideração na formulação de rações para alimentação animal, quando o custo de produção não é fator limitante (custo em R\$ para cada quilograma de NDT produzido nas distintas alturas de corte nesse estudo: $20 \mathrm{~cm}$ - R\$0,42; $50 \mathrm{~cm}$ - R\$0,44; $80 \mathrm{~cm}$ $\mathrm{R} \$ 0,47$ e $110 \mathrm{~cm}$ - R\$0,49 / dados não apresentados em tabelas). Pesquisas nessa área têm demonstrado o efeito benéfico da utilização dessa estratégia na nutrição animal, em situações onde o custo de produção não é limitante ou não é levado em consideração (BERNARD et al., 2004; NEUMANN et al., 2007; NEYLON; KUNG JUNIOR, 2003).

\section{Conclusões}

As características agronômicas e bromatológicas da silagem de milho melhoram com a elevação da altura de corte, mas a elevação da altura de corte inviabiliza economicamente a prática da ensilagem quando a geração de produtos finais não é computada. Desta maneira, recomenda-se que a altura de corte da planta de milho seja de no máximo $50 \mathrm{~cm}$.

\section{Referências}

ASSOCIATION OF OFFICIAL ANALYTICAL CHEMISTS - AOAC. Official methods of analysis, $16^{\text {th }}$ ed. Arlington, VA, 1996.

BERNARD, J. K.; WEST J. W.; TRAMMELL, D. S.; CROSS, G. H. Influence of corn variety and cutting height on nutritive value of silage fed to lactating dairy cows. Journal of Dairy Science, Champaign, v. 87, n. 7, p. 2172-2176, 2004.

CAETANO, H.; OLIVEIRA, M. D. S.; FREITAS JÚNIOR, J. E.; RÊGO, A. C.; RENNÓ, F. P.; CARVALHO, M. V. Evaluation of corn cultivars harvested at two cutting heights for ensilage. Revista Brasileira de Zootecnia, Viçosa, MG, v. 40, n. 1, p. 1219, 2011.

CAPPELLE, E. R.; VALADARES FILHO, S. C.; SILVA, J. F. C.; CECON, P. R. Estimativas no valor energético a partir de características químicas e bromatológicas dos alimentos. Revista Brasileira de Zootecnia, Viçosa, MG, v. 30, n. 6, p. 1837-1856, 2001.

DEMINICIS, B. B.; VIEIRA, H. D.; JARDIM, J. G.; ARAÚJO, S.A. C.; CHAMBELANETO,A.; OLIVEIRA, V. C.; LIMA, E. S. Silagem de milho - características agronômicas e considerações. Revista Electrónica de Veterinaria, Málaga, v. 10, n. 2, p. 1-18, 2009.

FERREIRA, D.F. Sisvar: a computer statistical analysis system. Ciência e Agrotecnologia, Lavras, v. 35, n. 6, p. 1039-1042, 2011.

FREITAS, A. W. P.; PEREIRA, J. C.; ROCHA, F. C.; DETMANN, E.; BARBOSA, M. H. P.; RIBEIRO, M. D.; COSTA, M. G. Avaliação da divergência nutricional de genótipos de cana-de-açúcar (Saccharum spp.). Revista Brasileira de Zootecnia, Viçosa, MG, v. 35, n. 1, p. 229236, 2006.

ÍTAVO, C. C. B. F.; MORAIS, M. G.; ÍTAVO, L. C. V.; SOUZA, A. R. D. L.; DAVY, F. C. A.; ALBERTINI, T. Z.; COSTA, C.; LEMPP, B.; JOBIM, C. C. Padrão de fermentação e composição química de silagens de grãos úmidos de milho e sorgo submetidas ou não a inoculação microbiana. Revista Brasileira de Zootecnia, Viçosa, MG, v. 35, n. 3, p. 655-664, 2006.

KUNG JUNIOR, L.; MOULDER, B. M.; MULROONEY, C. M.; TELLER, R. S.; SCHMIDT, R. J. The effect of silage cutting height on the nutritive value of a normal corn silage hybrid compared with Brown Midrib corn silage fed to lactating cows. Journal of Dairy Science, Champaign, v. 91, n. 4, p. 1451-1457, 2008.

LAUER, J. Corn silage yield and quality trade-offs when changing cutting height. Madison: Agronomy Advice, 
1998. Available at: <http://corn.agronomy.wisc.edu/ Publications/Aadvice/1998/CuttingHeightYieldAndQu alityTrade-OffForCornSilage.html>. Accessed at: 5 abr. 2013.

LEWIS, A. L.; COX, W. J.; CHERNEY, J. H. Hybrid, maturity, and cutting height interactions on corn forage yield and quality. Agronomy Journal, Madison, v. 96, n. 1, p. 267-274, 2004.

MILLEN, D. D.; PACHECO, R. D. L.; ARRIGONI, M. D. B.; GALYEAN, M. L.; VASCONCELOS, J. T. A snapshot of management practices and nutritional recommendations used by feedlot nutritionists in Brazil. Journal of Animal Science, Albany, v. 87, n. 10, p. 34273439, 2009.

NEUMANN, M.; MUHLBACH, P. R. F.; RESTLE, J.; OST, P. R.; LUSTOSA, S. B. C.; FALBO, M. K. Ensilagem de milho (Zea mays, L.) em diferentes alturas de corte e tamanho de partícula: produção, composição e utilização na terminação de bovinos em confinamento. Revista Brasileira de Milho e Sorgo, Sete Lagoas, v. 6, n. 3, p. 379-397, 2007.

NEYLON, J. M.; KUNG JUNIOR, L. Effects of cutting height and maturity on the nutritive value of corn silage for lactating cows. Journal of Dairy Science, Champaign, v. 86, n. 6, p. 2163-2169, 2003.

NUSSIO, L. G. Milho e sorgo para a produção de silagem. In: SANTOS, F. A. P.; NUSSIO, L. G.; SILVA, S. C. (Ed.). Volumosos para bovinos. Piracicaba: FEALQ, 1993. p. 75-177.

NUSSIO, L. G.; CAMPOS, F. P.; DIAS, F. N. Importância da qualidade da porção vegetativa no valor alimentício da silagem de milho. In: SIMPÓSIO SOBRE PRODUÇÃO E UTILIZAÇÃO DE FORRAGENS CONSERVADAS, 1., Maringá, 2001. Anais... Maringá: Universidade Estadual de Maringá, 2001. p. 127-145.

OLIVEIRA, F. C. L.; JOBIM, C. C.; SILVA, M. S.; CALIXTO JUNIOR, M.; BUMBIERIS JUNIOR, V. H.; ROMAN, J. Produtividade e valor nutricional da silagem de híbridos de milho em diferentes alturas de colheita. Revista Brasileira de Zootecnia, Viçosa, MG, v. 40, n. 4, p. 720-727, 2011.

PEDÓ, L. F. B.; NORNBERG, J. L.; PEDRO VELHO, J.; HENTZ, F.; HENN, J. D.; BARCELLOS, J. O. J.; HAYGERT VELHO, I. M. P.; MARX, F. R. Fracionamento dos carboidratos de silagens de milho safrinha colhidas em diferentes alturas de corte. Ciência Rural, Santa Maria, v. 39, n. 1, p. 188-194, 2009.

RABÊLO, F. H. S.; REZENDE, A. V.; RABELO, C. H. S.; AMORIM, F. A. Características agronômicas e bromatológicas do milho submetido a adubações com potássio na produção de silagem. Revista Ciência Agronômica, Fortaleza, v. 44, n. 3, p. 635-643, 2013 b.

RABÊLO, F. H. S.; REZENDE, A. V.; RABELO, C. H. S.; NOGUEIRA, D. A.; SILVA, W. A.; VIEIRA, P. F.; SANTOS, W. B. Consumo e desempenho de ovinos alimentados com silagens de cana-de-açúcar tratadas com óxido de cálcio e cloreto de sódio. Arquivo Brasileiro de Medicina Veterinária e Zootecnia, Belo Horizonte, v. 65, n. 4, p. 1158-1164, 2013a.

RESTLE, J.; NEUMANN, M.; BRONDANI, I. L.; PASCOAL, L. L.; SILVA, J. H. S.; PELLEGRINI, L. G.; SOUZA, A. N. M. Manipulação da altura de corte da planta de milho (Zea mays L.) para ensilagem visando a produção do novilho superprecoce. Revista Brasileira de Zootecnia, Viçosa, MG, v. 31, n. 3, p. 1235-1244, 2002.

RODRIGUES, R. C. Avaliação químico-bromatológica de alimentos produzidos em terras baixas para nutrição animal. Pelotas: EMBRAPA, 2009. 31 p. (Documentos, 270).

SILVA, D. J.; QUEIROZ, A. C. Análise de alimentos: métodos químicos e biológicos. 3. ed. Viçosa, MG: UFV, 2002. $235 \mathrm{p}$.

VAN SOEST, P. J. Nutritional ecology of the ruminant. $2^{\text {th }}$ ed. Ithaca: Cornell University Press, 1994. 476 p.

VAN SOEST, P. J.; ROBERTSON, J. B. Analysis of forages and fibrous foods. Ithaca: Cornell University Press, 1985. 202 p.

VAN SOEST, P. J.; ROBERTSON, J. B.; LEWIS, B. A. Methods for dietary fiber, neutral detergent fiber, and nonstarch polysaccharides in relation to animal nutrition. Journal of Dairy Science, Champaign, v. 74, n. 10, p. 3583-3597, 1991.

VASCONCELOS, R. C.; VON PINHO, R. G.; REZENDE, A. V.; PEREIRA, M. N.; BRITO, A. H. Efeito da altura de corte das plantas na produtividade de matéria seca e em características bromatológicas da forragem de milho. Ciência e Agrotecnologia, Lavras, v. 29, n. 6, p. 1139-1145, 2005.

VAZ, F. N.; RESTLE, J.; EIFERT, E. C.; BRONDANI, I. L.; VAZ, R. Z.; ARGENTA, F. M. Efeitos da altura de colheita da silagem de milho e do nível de concentrado sobre as características da carcaça e da carne de novilhos super jovens. Ciência Animal Brasileira, Goiânia, v. 11, n. 2 , p. $315-325,2010$.

WU, Z.; ROTH, G. Considerations in managing cutting height of corn silage. College Park: Pennsylvania State University, 2005. 7 p. (Extension publication DAS). 
